\title{
Research on the Application of Zero Equivalence Translation Theory in the Creative Industry Practice of Ceramic Culture from the Perspective of Globalization
}

\author{
Jing Lin \\ Jingdezhen Ceramic University, Science and Technology College, Jingdezhen, Jiangxi, China, 333000
}

Keywords: Zero Equivalence, Ceramics, Globalization, Cultural and Creative Industries

\begin{abstract}
In the context of globalization, ceramic art as a traditional Chinese culture gradually out of the country, and in the international arena cut a striking figure, but the current translation of ceramic culture in the initial stage, the basis of weak, uneven translation levels, research fragmentation. Ceramic culture English translation is lagging and a series of factors affecting the ceramic culture industry internationalization. Under the background of the intensification of cultural globalization, the English translation of ceramic culture has broad prospects for development in disciplinary construction, practical application and academic research.
\end{abstract}

\section{Introduction}

At present, the phenomenon of globalization is very serious, the world culture is still in Europe and the United States under the main cultural rule, the new cultural colonization is a new way to accelerate development. Facing the strong impact of the mainstream culture of Europe and the United States, the traditional Chinese culture in line with the world at the same time, we must accurately locate, highlight the Chinese elements and strengthen their own development, the implementation of cultural strategy breakthrough. As one of Chinese cultural treasures, ceramic culture is also facing the impact of the wave of globalization and its development is both opportunities and challenges. Especially with the construction of the Central Plains Economic Zone to rise to national strategy to build the history of Chinese civilization and cultural innovation area has become one of the five strategies to ceramic art as the representative of the Central Plains culture is facing great opportunities for development, ceramic cultural industry should make full use of the current policy advantages, combined with the global development situation, based on their own development, to promote the internationalization process. And the art of ceramics to the world, English translation is an extremely important issue and it is to a large extent affect the internationalization of ceramic culture process.

\section{The Present Situation and Problems of English Translation of Ceramic Culture}

Ceramics as one of Chinese major porcelain, its international development and other domestic porcelain culture is relatively lagging behind, especially in ceramic English translation, almost in the blank stage. Ceramic English as a course of the opening of the situation is not very optimistic, limited to a few ceramic colleges and universities, and mainly vocational colleges, the content is mainly vocabulary collection and translation of ceramic literature, there is no systematic system of ceramics development to do a deep level of combing, resulting in the opening of the course is not very good effect, which is currently the development of Chinese industry, a lack of English links. The creation of ceramic English courses in the ceramic source of Xuchang Institute is still in the research stage, although it has caused the attention and research departments concerned, is actively preparing, but has not yet entered the stage of practice. At present, ceramic English translation is only reflected in the following aspects:

The translation of ceramic-related terms, such as the translation of the name of the ceramic, the 
general translation for the Jomon pottery, ceramics, fine China, this is a ceramic name of the translation on a wide variety. Translation can be diversified, but the translation of the proper name of a thing should not be too diversified, which is not conducive to its external spread, because in its external communication process easy to make the recipient misunderstanding, and thus can not accurately grasp the nature of things The In addition to the standardization of the translation of the terms of the ceramic name, the translation of other ceramic terms is quite mixed, depending entirely on the subjective will of the translator. That is, in the current situation, the English translation of the ceramic term is in a straggous stage, without a standardized industry and professional standards.

The ceramic translation is more common in the introduction of ceramic enterprises and ceramic artifacts and so on. For example, to hole Jiajun kiln, the Song Dynasty kiln Rongchang ceramic Square, Miao Jiajun kiln, Jin Jiajun kiln as the main body of the ceramic business community, their own company for a simple English introduction. These English translation is simply on the origin of ceramics, ceramic characteristics, the company's history has been described, and the company's products are not systematic English translation, is the company's leading products, such as national ceremony products did not do the corresponding English translation, At best, is a "four not like" the name of the product translation, and the product contains the cultural information is not observed. Such as ceramic "dragon first respect", can be translated as "Dragonhead zun", this translation intuitive clear, but this for the world audience, especially in Western countries, may bring cultural ambiguity, mainly "dragon" in the East and West culture The meaning of the contrary, in China, "dragon" is a symbol of auspicious and luxurious, and in the West is a symbol of evil, so the name of the translation should be "dragon" cultural interpretation; In addition, still need to "respect" the Chinese unique containers for auxiliary instructions, otherwise it will give the recipient a cultural understanding of obstacles. From the ceramic enterprises on the relevant English translation practices and attitudes, you can glimpse the industry on the international market is not fully prepared.

Ceramic translation found in the scenic area of publicity, logo, etc., as well as foreign institutions and ceramic culture research institutions publicity. Such as ceramic museums, magistrates and kiln sites, in their institutions introduced in English for a simple translation, and in the key attractions and ceramic history on the use of English translation. In addition, in the town of god town ceramic landscape, in addition to the introduction of the scenic area, the entire town of the logo also used the English translation. And then there is foreign affairs agencies of the external publicity and reception exchanges, will hire a special translation to promote and on-site translation.

Ceramic translation is found in the network media, mainly reflected in several aspects: the official website of ceramic enterprises have a certain number of English translation, the first is the name of the enterprise and the name of the site translation; and then the foreign information and products of English introduction; That is, a large number of online stores in the release of product information and product introduction using English translation, these translations are not a system, there is no uniform standard, resulting in uneven translation level; then there are some well-known forum, blog on ceramic culture information, ceramics product appreciation, mainly foreign favorite Chinese ceramic culture of experts and scholars on the English assessment of ceramics and so on.

Ceramic translation is seen in recent years on the relatively frequent ceramic exposition activities and held for many years on the Ceramic International Cultural Festival. In recent years, under the call of national culture and great prosperity and development policy, local traditional culture has gradually come out of the local, ceramics have many times in Hong Kong, South Korea, Japan, the United States and other cultural relics held large-scale exhibition promotion to a certain extent, promote the ceramic communication, but because of the lack of translation and many other factors, the internationalization of ceramics has been greatly restricted. In addition, in the domestic ceramic international cultural festival as the representative of the exhibition activities, floating in the form of internationalization is not deep and did not achieve the desired results including ceramic culture translation is a prominent constraint. 


\section{The Countermeasure of Ceramic Business English Translation from the Perspective of the Theory of Zero Equivalence Theory}

Ceramic business English translation, in order to achieve efficient communication, must be done in two aspects of functional equivalence, one is naturalized translation, and the other is a direct conversion. Among them, the direct conversion is to do semantic and style and other aspects of the same, and naturalized translation is to meet the original center, the correct understanding of professional terms and in line with the translation style.

\subsection{Vocabulary Translation Does the Term Equivalence}

Ceramic business English translation involves more content, which means that in real-time translation links, there will be a large number of professional terms appear, the translator can use the literal translation method, such as flies can be directly translated into " " However, in many cases, transliteration in the literal meaning of the understanding of the ceramic trading side will cause trouble, for example, according to the literal meaning translated as "good China", but its intended "fine porcelain." Therefore, the translator must not ignore the important principle of terminology equivalence, should be accurate understanding of the terminology at the same time and select the norms and professional words to start translation, so that communication can be carried out smoothly.

\subsection{The Translation of the Sentence should be Meaningful and Communicative Role Equivalence}

In the process of translation of ceramic business English sentences, there are two kinds of simple sentences and lengthy compound sentences. For simple sentences, if direct translation is used to obtain the equivalence between the source language and the target language in the language extension and connotation, then the direct translation method is used boldly to realize its equivalence in structure, and finally functional equivalence. In the face of the ceramic business English contract which involves the legal provisions, contract terms and content integrity of the lengthy sentence, the majority of translation workers must not only pursue the appearance of reciprocity, we must figure out the logical structure of the statement and the central idea and then according to the provisions of the translation to implement the translation work to achieve effective communication.

\subsection{The Overall Translation of the Discourse Does Not Deviate from the Original Center}

In the translation of large paragraph or chapter type of ceramic business English, the translator must take full account of the content of the untranslatability, based on the theory of zero equivalence, a comprehensive grasp of our country and the West in this aspect of communication language and the corresponding culture background, precise grasp of the overall language of the stylistic characteristics, tone, style and a comprehensive grasp of its central ideas, in order to achieve the actual meaning and formal structure of the equivalent [3].

\section{The Practice Application of Ceramic Culture and Creative Industries Zero Translation Theory from the Perspective of Globalization}

Through the analysis of the status quo of ceramic English translation, it is found that there are a series of problems, such as late start, weak early stage, low scale, narrow translation range, uneven level and insufficient attention. The emergence of these problems has profound social reasons, political reasons and cultural reasons. In the case of language and culture alone, the translators were asked. Ceramics is the crystallization of Chinese scientific and technological civilization, contains a series of complex processes, since ancient times there are "seventy-two" process, according to the current technology, including: processing, modeling, molding, burning, glazed, glaze burning, inspection and so on. Therefore, the translation of ceramics is largely a scientific and technological translation, which requires the translation of ceramics in strict accordance with the standards of 
scientific and technological translation, for the international market, the language seeks accurate, refined.

However, ceramic art as one of the intangible cultural heritage of the Chinese nation, with profound cultural connotation and historical accumulation, coupled with the rich local characteristics of Yuzhou, and thus ceramic translation and literary translation, cultural translation is inextricably linked from To some extent that the ceramic transmission is a cultural information, ceramic art at home and abroad is a cross-cultural communication process. This requires the translation of the ceramic embodies the characteristics of literary translation, both faithful to the original, but also has a profound cultural atmosphere, because the ceramic culture translation and ceramic external communication is the ceramic art to achieve an important level. And translation is a translation of a language into another language of creative activities and the so-called creation is the translator's understanding and the true meaning of the original rational combination, both true meaning, but also to show the translator's personalized understanding. At the same time, it means that translation not only needs to convey the meaning of the source text closest to reality, but also to convey its implicit cultural meaning and aesthetic meaning creatively, so that the input language reader can understand the meaning of the text, people understand their cultural information and aesthetic significance. This translation is in line with the translation of the superior standards. In the process of accepting the reader, the reader does not accept the meaning of the text, but takes the initiative to participate and penetrate into the construction of the meaning of the text.

Recipient achieve the cultural information symbol conversion and the construction of the meaning of the text through the creative activities, which is the translation value realization way and platform. Ceramic art as an important social and cultural resources, with a strong social, it reflects the vast number of consumers, especially cultural consumers to the pursuit of beauty. Ceramic culture should follow the social habits and cultural traditions, it is necessary to cater to the aesthetic needs of mass consumers, but also to convey the essence of Chinese culture, enhance the aesthetic connotation of ceramic culture, to achieve cultural cross-border communication. It is very necessary to apply the aesthetic theory to the needs of the ceramic culture, and pay more attention to the acceptance ability of the consumers at all levels, realize the social value of the ceramic culture and promote the aesthetic value of the ceramic culture deepen.

\section{Conclusion}

To sum up, the tide of globalization has intensified, and the opportunities of Chinese traditional culture to the world are increasing. The situation of opportunity and challenge is deepening. Ceramic art must be strengthened in the world culture. So that it can be with the world, and the world dialogue, but also to highlight the elements of Chinese characteristics in the world, take the real international road, the real implementation of the "national" is the "world" brand strategy.

\section{Acknowledgements}

Fund Project: National College of Foreign Language Teaching and Research Project, No.: Gan -0012-A, the name: "Research on the Application of Zero - pair Translation Theory in the Creative Industry Practice of Ceramic Culture from the Perspective of Globalization ".

\section{References}

[1] Yu Xiang Yue. Business English translation and teaching inspiration from the perspective of schema[J]. Journal of Inner Mongolia Normal University (Education Science Edition), 2016, 29 (10): 133-137.

[2] QI Fen.Application of Functional Translation Skopos Theory in Business English Translation [J]. Journal of Changsha Railway Institute (Social Science Edition), 2013, 14 (4): 202-203.

[3] Wang Qing. From the functional point of view of business English translation principles and strategies[J]. Campus English (mid-year), 2015,15 (4): 227-228. 